consultant in mental handicap. Our psychiatric expertise is becoming increasingly recognised but as community care develops there is some uncertainty about our future role which will continue until specialist treatment facilities are established which will make the best use of our time and expertise.

DAVID H. JAMES

Rosevear, Budock Hospital

Falmouth, Cornwall

\section{What should registrars and senior registrars learn about mental handicap?}

DeAR SiRS

Registrars and senior registrars assigned to work in mental handicap for the first time can feel at a loss. Their work does not necessarily assume the patterns that general and acute commitments automatically impose. In mental handicap, patients' problems often tend to be long-term, to involve a range of disciplines and services and to be less immediately responsive to therapeutic interventions. At a hospital for mental handicap, trainees will be faced with large numbers of patients, only some of whom intermittently or continuously have psychiatric disorders and needs.

It is, therefore, especially important to give the trainees some structure and purpose to their clinical activities, duties and experience, which can add flesh to the skeleton of broad objectives that the Royal College of Psychiatrists (1985) has outlined. Mental handicap has the advantage of encompassing a reasonably distinct body of knowledge and practice. This makes it possible to compile a checklist of subjects of which trainees need to be aware, and with which they can plan to gain familiarity. A package of training could be devised, to be treated as flexible, tailored to the requirements of individual trainees related to their previous studies of the topics involved and whether they are at registrar or senior registrar level.

For example, trainees could aim to cover the following topics. The headlines are broad so that detail can be expanded under each item.

\section{(a) Background}

Outline of history of mental handicap and services, terminology, definitions, conceptions, criteria, prevalence, classification, aetiology, epidemiology, clinical features of the more common conditions, prevention - primary, secondary, tertiary.

\section{(b) The health care of people with mental handicaps}

General medical care - susceptibility of people with mentally handicapping conditions to particular medical disorders. Specialist needs-physical disabilities, epilepsy, sensory handicaps, speech and communication difficulties, conduct and behaviour disorders, profoundly mentally and physically handicapped people-physiotherapy, mobility and orthopaedic help, nutritional needs and advice.

\section{(c) Life, family and community processes and services}

The problems, needs and provisions associated with mentally handicapped people and their families and carers from infancy, through childhood and adolescence to adult life and old age; child development and assessment; primary care and community mental handicap teams; options in residential care, education, training, work, leisure and recreation, rehabilitation, individual programme planning and resettlement. Planning of services; mental handicap registers; contributions of voluntary agencies.

\section{(d) The psychiatry of mental handicap}

Psychoneurotic and psychotic disorders in mentally handicapped patients, classification, differences in presentation of mental illness in mental handicap. Epilepsy and mental handicap. Autistic syndromes. Dementia in mentally handicapped people. Challenging behaviours. The Mental Health Act and mental handicap-mental impairment. Forensic mental handicap - mentally handicapped offenders, interrogation of mentally handicapped persons, reports to Courts, 'difficult to place' patients, intensive care and special needs cases, visits or residential period for experience at a special hospital.

\section{(e) Clinical practice}

History-taking, examination, formulation of reports. Out-patient clinics, community visits, inpatient reviews, case conferences, monitoring of medication, consent to treatment issues.

\section{(f) General}

Timetable, text books, mental handicap journals, reading lists on mental handicap, management involvement, research opportunities.

Meanwood Park Hospital

Douglas A. SPEncer

Leeds LS6 4QD

\section{Reference}

Royal College of Psychiatrists (1985) (Section for the Psychiatry of Mental Handicap) Registrar training in mental handicap. Bulletin of the Royal College of Psychiatrists, 9, 206 